Journal of Advanced Research in Fluid Mechanics and Thermal Sciences

Journal homepage: www.akademiabaru.com/arfmts.html ISSN: 2289-7879

\title{
Phase Transitions in Casting Process of Beryllium Oxide Slip
}

\author{
Bagdaulet Kenzhaliyev, Uzak Zhapbasbayev2,*, Gaukhar Ramazanova², Arman Shah³, Gennady \\ Bitsoyev ${ }^{4}$ \\ 1 Institute of Metallurgy and Ore Benefication, 050000, Almaty, 29 Shevchenko str., Republic of Kazakhstan \\ Satbayev University, 050013 Almaty, 22 Satbaev str., Republic of Kazakhstan \\ Faculty of Technical and Vocational, Universiti Pendidikan Sultan Idris, Perak, Malaysia \\ 4 East Kazakhstan State Technical University, 070004 Ust-Kamenogorsk, 69 Protozanov str., Republic of Kazakhstan
}

\section{ARTICLE INFO ABSTRACT}

\section{Article history:}

Received 29 April 2020

Received in revised form 30 July 2020

Accepted 8 August 2020

Available online 25 September 2020

\section{Keywords:}

Casting process; Phase transitions; Liquid state; Solidification; Viscous-plastic state

\begin{abstract}
Beryllium oxide slip casting is used to obtain products of complex shapes of various designs. Ultrasonic activation improves the rheological properties of the beryllium oxide slip. In experiments with ultrasonic activation, physicochemical properties of a beryllium oxide slip were obtained. The calculated beryllium oxide casting data was obtained using the Balkley-Herschel model. The phase transition from liquid to viscousplastic state indicates the presence of a crystallization zone consisting of liquid and solid particles of beryllium oxide. Comparison of calculated data with experiment is presented.
\end{abstract}

Copyright $\odot 2020$ PENERBIT AKADEMIA BARU - All rights reserved

\section{Introduction}

Ceramic fabrications of beryllium oxide $(\mathrm{BeO})$ have unique physico-chemical properties that combine with high chemical, thermal, radiation resistance, thermal conductivity, and transparency for vacuum ultraviolet, $x$-ray, and microwave radiation [1-7]. The listed properties of $\mathrm{BeO}$ make it an advanced material for use in electronics, radio engineering, instrumentation, nuclear reactors, and etc [1]. The production of beryllium ceramic is carried out by complex properties and structural homogeneity during hydrodynamic, relaxation, and physico-chemical processes taking place at the formation stage. The casting process of $\mathrm{BeO}$ slip imposes really rigorous specifications on the product properties and has considerable complexity, which is foremost due to high thermal conductivity. As a result, in practice, mouldings are not of required quality, productiveness is low and output of items is poor due to the complexity of controlling the structure formation of a semi-finished product. A significant role in the homogeneous structure formation of the resulting products plays an ultrasonic (US) activation effect [8].

\footnotetext{
* Corresponding author.

E-mail address: uzak.zh@mail.ru

https://doi.org/10.37934/arfmts.75.3.126139
} 
A number of works are devoted to various aspects of the preparation and casting of BeO slips [27]. In this case the difficulty in obtaining high-quality products is caused, first of all, by the thermophysical properties of $\mathrm{BeO}$, in particular, its unique thermal conductivity $[6,7]$. High heat conductivity of disperse medium complicates management of structure formation of the semifinished product while moulding. Increase of liquid phase in volume for increase of necessary moulding properties of slip does not allow achieving required effect. While roasing "additional" amount of binder leads to the appearance of structural defects and deformation of the products. Technological methods, connected with temperature and pressure increase, do not give desirable result too. In this connection, to improve products quality and increase moulding productiveness it is advisable to use dynamic methods. Ultrasonic activation is one of the most effective methods of such type [9].

Slip casting technology includes the stages [1]: the motion and heat exchange in liquid state; the motion and heat exchange with regard for crystallization; the motion and heat exchange of the cast in the solid state. At the stage of filling the forming cavity and holding under pressure, it is most important to ensure the maximum impacts ultrasonic activation to obtain a homogeneous suspension. This is achieved by Ultrasonic effect [1]. In the process of hardening, it is necessary to achieve minimal friction against the walls of the forming cavity and maximum ductility without destroying the structure of the casting.

The hydrodynamics of slip during casting should be viewed as a physical process of deformation and flow. The slip flow retains its configuration after exiting the feeder. The experiments have established that in the range of possible casting rates the flow of slip in a casting mold is laminar [1]. Slip enters the casting mold at temperature $75-80^{\circ} \mathrm{C}$ and cools in the mold till $40-45^{\circ} \mathrm{C}$, at which the cast can be extracted from the mold without being distorted.

The technology of slip casting is very relevant in connection with intensive development of the metal injection molding, where similar physical processes take place [10].

The creation and realization of the hot casting method has been carried out empirically $[1,6,7]$. Below are the results of modeling the process of molding beryllium oxide ceramics by hot casting.

\section{Experimental Data of Thermoplastic Slip}

The thermoplastic slip (high-viscosity suspension) is a two-phase disperse system, where the solid mineral phase is a beryllium oxide powder while the liquid phase is an organic binder [1,3-7]. The organic binder consists of three components: paraffin, beeswax, and oleic acid in the mass ratio (wt.\%) 82:15:3. BeO powder has a granulometric composition by fractions (Table 1). Mass fraction of organic binder is changed in the range of 0.095-0.117.

Molding properties of the slip are satisfactory for this composition of the BeO powder (Table 1), if the binder mass content $\omega$ is varied from 0.095 to 0.117 . The required amount of binder $\omega$ rises with increasing number of finer fractions in the $\mathrm{BeO}$ powder. An increase of the number of coarser fractions in the $\mathrm{BeO}$ powder causes a coloring of ceramic, which is sign of presence of micro pores and cracks [1].

Experiments to study the forming process of a thermoplastic BeO slip are described in detail in [1]. The liquid slip flows along the vertical annular cavity of the casting installation with an initial temperature $\mathrm{TO}=80^{\circ} \mathrm{C}$. It changes the aggregation state, and passes from the liquid state to the viscous-plastic state with the formation of a crystalline structure and into the solid-plastic state with solidification. The change of state zone of the $\mathrm{BeO}$ slip can occupy a region limited with the solidus isotherms $\left(\mathrm{Tw}=54^{\circ} \mathrm{C}\right)$ and $\left(\mathrm{Tw}=40^{\circ} \mathrm{C}\right)[11]$. 


\section{Table 1}

Main characteristics of the beryllium oxide powder

\begin{tabular}{lll}
\hline Bulk weight $\rho 0 \times 10^{3} \mathrm{~kg} / \mathrm{m}^{3}$ & 0.75 \\
\hline Specific surface area, $\mathrm{S} \cdot 10^{-3} \mathrm{~m}^{2} / \mathrm{kg}$ & 1.72 \\
\hline Particle size distribution of BeO powder & Fraction, $\mu \mathrm{m}$ & Content, \% \\
& up to 1.4 & 35.2 \\
& $1.4-4.2$ & 52.7 \\
& $4.2-7.0$ & 9.6 \\
& $7.0-9.8$ & 1.7 \\
& $9.3-12.6$ & 0.4 \\
& $12.6-15.4$ & 0.3 \\
\hline
\end{tabular}

The total amount of latent heat $\Delta \mathrm{H}$ can be determined by the apparent heat capacity method [12-17]. In this case, the change in heat capacity can be represented as [12]-[15]

$c_{p}=\left\{\begin{array}{l}c_{s}, \quad t<t_{s}, \quad \text { in solid state } \\ c_{\text {in }}, \quad t_{s} \leq t \leq t_{l}, \text { in transition zone } \\ c_{l}, \quad t>t_{l}, \quad \text { in liquid state }\end{array}\right.$

where $c_{i n}=\left\{\int_{t_{s}}^{t_{l}} c_{l}(t) d t+H_{1 \rightarrow 2}\right\} /\left(t_{l}-t_{s}\right), H_{1 \rightarrow 2}$ is the phase transition specific enthalpy of BeO slip is determined by experiments [18].

The experimental data [1] of the temperature dependence of the slip heat capacity for the mass fraction of the binder $\omega=0.117$ are described by the empirical formula

$c_{l}(t)=70+1070 \cdot \exp (0.0027 \cdot t), \mathrm{J} /\left(\mathrm{kg} \cdot{ }^{\circ} \mathrm{C}\right)$

Substituting $c_{l}(t)$ into the integral $c_{i n}$ of the Eq. (1), we can determine the dependence of the slip heat capacity on temperature in the transition zone.

The experimental data of the dependences of viscosity, shear yield stress, and thermal conductivity on temperature at $\omega=0.117$ are described by the empirical Eq. (3)-(5) [1]

$\mu(t)=293.6259 \cdot \exp (-0.05816 \cdot t), \mathrm{Pa} \cdot \mathrm{s}$

$\tau_{0}(t)=11.4+11.41 \cdot \exp (-(t-70.06) / 5.46), \mathrm{Pa}$

$\lambda(t)=1.6+4.8 \cdot \exp (-0.017 \cdot t), \mathrm{W} /\left(\mathrm{m} \cdot{ }^{\circ} \mathrm{C}\right)$

Similarly, for the binder $\omega=0.10$ the experimental data of the temperature dependence of the thermal properties of the slip are expressed by the empirical formulas [1]

$c_{l}(t)=10+1070 \cdot \exp (-0.0027 \cdot t), \mathrm{J} /\left(\mathrm{kg} \cdot{ }^{\circ} \mathrm{C}\right)$

$\mu(t)=4440.958 \cdot \exp (-0.09068 \cdot t), \mathrm{Pa} \cdot \mathrm{s}$

$\tau_{0}(t)=762.1393 \cdot \exp (-0.04968 \cdot t), \mathrm{Pa}$

$\lambda(t)=7.1 \cdot \exp (-0.01 \cdot t), \mathrm{W} /\left(\mathrm{m} \cdot{ }^{\circ} \mathrm{C}\right)$

The density of thermoplastic slip is determined by the concentrations of the $\mathrm{BeO}$ powder and the binder 
$\rho=\frac{\rho_{m b} \cdot \rho_{c b}}{(1-\omega) \cdot \rho_{c b}+\omega \cdot \rho_{m b}},\left(\mathrm{~kg} / \mathrm{m}^{3}\right)$

where $\rho_{m b}$ is the density of the $\mathrm{BeO}, \rho_{c b}$ is the density of the binder, $\omega$ is specific mass content of the binder in the fractions.

The density of the binder [1] is determined by the Eq. (8)

$\rho_{c b}(t)=0.8485+0.0755 \cdot \cos (0.0571 \cdot t-1.1392), \times 10^{3}\left(\mathrm{~kg} / \mathrm{m}^{3}\right)$

The density of the beryllia is $\rho_{m b}=3020 \mathrm{~kg} / \mathrm{m}^{3}$. The density of the binder in the range of temperature from $80^{\circ} \mathrm{C}$ to $40^{\circ} \mathrm{C}$ changed within 775.9 to $880.3 \mathrm{~kg} / \mathrm{m}^{3}$ and the density of the thermoplastic slip during solidification increases from 2345 to $2425 \mathrm{~kg} / \mathrm{m}^{3}$ for the fraction $\omega=0.100$.

The thermophysical properties of the beryllium oxide slip are determined by the empirical Eq. (1)-(8). In the casting mould, there is a transition of the liquid suspension into a solid state.

\section{Thermomechanical Model}

A motion and a heat exchange of the $\mathrm{BeO}$ thermoplastic slip in a forming bushing of the casting installation are considered [1]. The mold cavity has a flat shape (Figure 1(a)) or an annular shape (Figure 1(b)).

The flat cavity has a thickness of $2 \mathrm{~h}=0.0015 \mathrm{~m}$, a width of $B=0.03 \mathrm{~m}$ and a length of $L=0.035 \mathrm{~m}$. The annular cavity dimensions are $r_{1}=0.015 \mathrm{~m}, r_{2}=0.016 \mathrm{~m}, L=0.089 \mathrm{~m}$. The cooling circuit of the bushing is divided into three parts. Temperature of the cooling water in the first part is $\vartheta_{1}=80^{\circ} \mathrm{C}$, in the second part is $\vartheta_{2}=54^{\circ} \mathrm{C}$, in the third part is $\vartheta_{3}=40^{\circ} \mathrm{C}$. The liquid slip with initial temperature $t_{0}=$ $80^{\circ} \mathrm{C}$ flows into a cavity, cools and solidifies while moving. It acquiring structural form on the exit from the molding cavity. The thermoplastic slip flows in the laminar mode. The density of the slip is variable and increases with solidification.

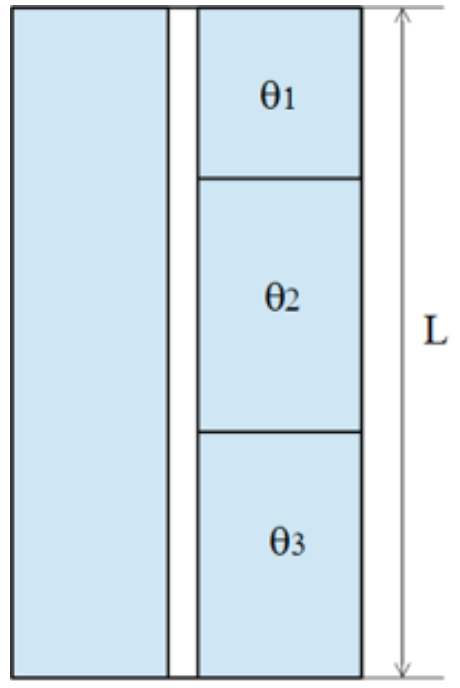

(a)

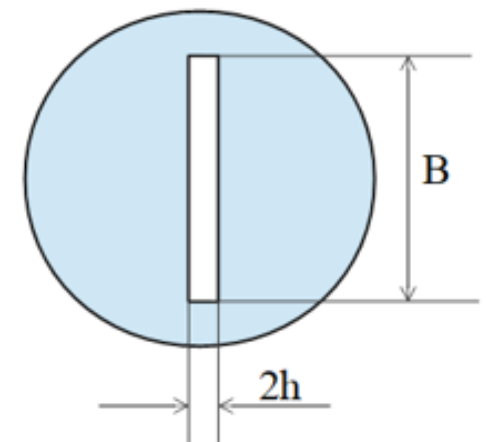

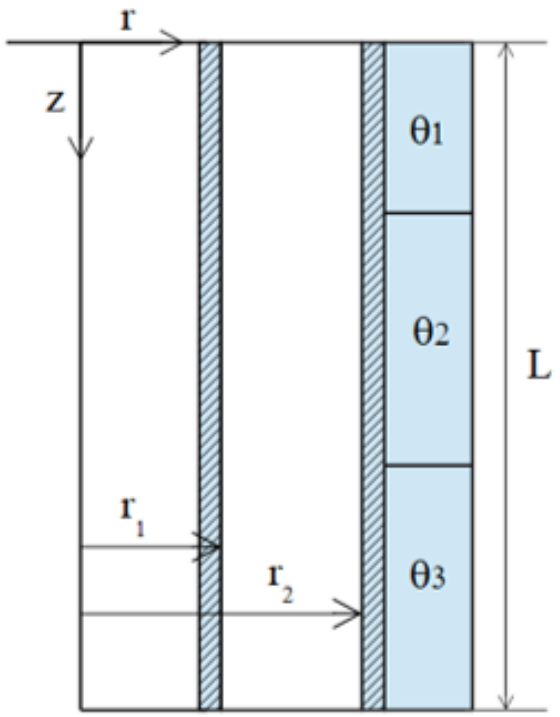

(b)

Fig. 1. Bushing diagram: (a) flat shape cavity; (b) annular shape cavity

In the experiments Shakhov [3]-[5] a liquid slip of beryllium oxide shows a rheology of a nonNewtonian Balkley-Herschel fluid [19]. The movement of the slip in the forming cavity is considered 
stationary, and for study the motion and heat transfer of the slip the system of equations in a narrowchannel is used

$\rho u \frac{\partial u}{\partial z}+\rho v \frac{\partial u}{\partial r}=-\frac{d p}{d z}+\frac{1}{r^{k}} \frac{\partial}{\partial r}\left(r^{k} \mu\left|\frac{\partial u}{\partial r}\right|^{n-1} \frac{\partial u}{\partial r}\right)-\frac{1}{r^{k}} \frac{\partial}{\partial r}\left(r^{k} \tau_{0}\right)$

$\frac{\partial \rho u}{\partial z}+\frac{1}{r^{k}} \frac{\partial r^{k} \rho v}{\partial r}=0$

As the slip moves conductive heat transfer occurs in the longitudinal and transverse directions of the cavity. The latent heat of phase transition is determined by the apparent thermal capacity model (1).

In the steady-state process of slip forming, the heat transfer equation, taking into account the accepted assumptions, can be written in the form $[13,20]$

$\rho u c_{p} \frac{\partial t}{\partial z}+\rho v c_{p} \frac{\partial t}{\partial r}=\frac{\partial}{\partial z}\left(\lambda \frac{\partial t}{\partial z}\right)+\frac{1}{r^{k}} \frac{\partial}{\partial r}\left(r^{k} \lambda \frac{\partial t}{\partial r}\right)$

The following notations are used in the Eq. (9)-(11): $z, r$ are axial and radial coordinates; $u, v$ are components of the velocity vector; $p, \rho, t, \tau_{0}, c_{p}, \mu, \lambda$ are pressure, density, temperature, shear stress, coefficients of apparent thermal capacity, viscosity and thermal conductivity of the slip, respectively.

The system of Eq. (9)-(11) describe the formation process in a flat cavity for $k=0$ and in the annular cavity for $k=1$.

The thermophysical properties of the slip are expressed by the empirical Eq. (1)-(8). Condition of the mass flow rate conservation allows to determine the pressure gradient for the thermoplastic slip extruding from the casting mold [21]

$\iint \rho u d s=\rho_{o} u_{o} S_{0}$

where $S_{0}$ is cross-section area of the cavity.

The boundary conditions for the flat cavity are given in [13]. The following boundary conditions are put at the entrance of the annular cavity

$u=u_{0}, v=0, t=t_{0}$ for $z=0$

For the liquid slip the following conditions are placed on the inner wall of the annual cavity

$u=v=0, \frac{\partial t}{\partial r}=0$ for $0 \leq z \leq l_{1}, r=r_{1}$

For the liquid slip the following conditions are set on the outer wall of the annual cavity

$u=v=0, t=\theta_{1}$ for $0 \leq z \leq l_{1}, r=r_{2}$

In the field of crystallization and solidification of the slip the following conditions for speed and temperature are placed on the walls of the annular cavity 
$\frac{\partial u}{\partial r}=0, v=0$ for $z>l_{1}, r=r_{1}, r=r_{2}$

$\frac{\partial t}{\partial r}=0$ for $l_{1} \leq z<l_{2}, r=r_{1}$ and $t=\theta_{2}$ for $l_{1} \leq z<l_{2}, r=r_{2}$

$\frac{\partial t}{\partial r}=0$, for $l_{2} \leq z<l_{3}, r=r_{1}$ and $t=\theta_{3}$ for $l_{2} \leq z<l_{3}, r=r_{2}$

For the temperature at the outlet of the annular cavity the following boundary condition is set

$\frac{\partial t}{\partial z}=0$ for $z \geq l_{3}$

For convenience of solution, the system of Eq. (1)-(19) is reduced to dimensionless form. The coordinates $z, r$ are divided by $r_{1}$, the velocity components $u, v$ by $u_{0}$, the pressure $p$ by the dynamic head $\rho_{0} u_{0}^{2}$, the temperature $t$ by $t_{0}$, and the density, shear stress, coefficients of specific heat, viscosity, and thermal conductivity by their values at the temperature $t_{0}$.

The system of Eq. (1)-(12) is solved numerically at boundary conditions of Eq. (13)-(19) [21,22]. The considered zone is divided into elementary cells with sides $\Delta z_{i}, \Delta r_{j}$. Different analogs of the motion Eq. (9) and energy Eq. (11) were obtained by the Crank-Nicolson method of the second order precision, but difference analog of Eq. (10) was obtained by two-layer scheme of the second order precision [21,22]. Pressure gradient is defined by the splitting method from the condition of conservation of mass flow of Eq. (12) [21,22].

\section{Verification of Calculated Data}

Verification of the calculation results was carried out according to the experimental data Shakhov and Bitsoev [1] obtained in the flat cavity for the beryllium oxide ceramic. The calculations are carried out with the same operating conditions of the experiments (see Table 2).

Figure 2 presents the calculated data on the distribution of slip temperature and density in the flat cavity at the binder concentration of $\omega=0.100$. At the inlet of the flat cavity, the temperature of the slip is constant and equal to $t_{0}=80^{\circ} \mathrm{C}$. In the zone of the hot circuit with water temperature $\vartheta_{1}=$ $80^{\circ} \mathrm{C}$, the slip is in a liquid state.

In the warm circuit zone of with water temperature $\vartheta_{2}=54^{\circ} \mathrm{C}$, heat transfer occurs between the hot slip and warm water, and the cooling of the slip mass begins. In the solidification zone between the isotherms $56^{\circ} \mathrm{C}$ and $42^{\circ} \mathrm{C}$, the slip transfers from the liquid state to the solid state. It is also seen in the slip density distribution (Figure 2).

Figure 3 illustrates the temperature and density distributions of a beryllium oxide slip in the flat cavity at the binder concentration $\omega=0.117$. 


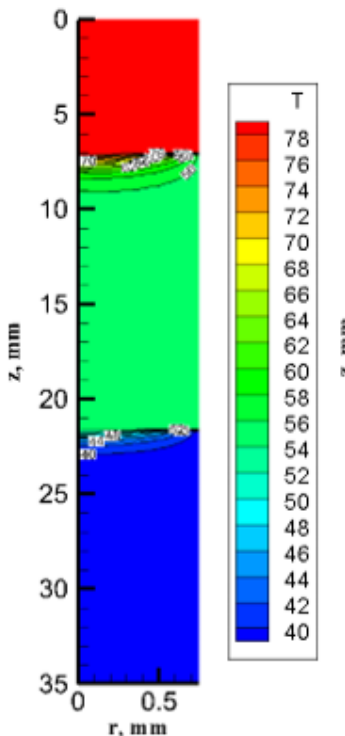

(a)

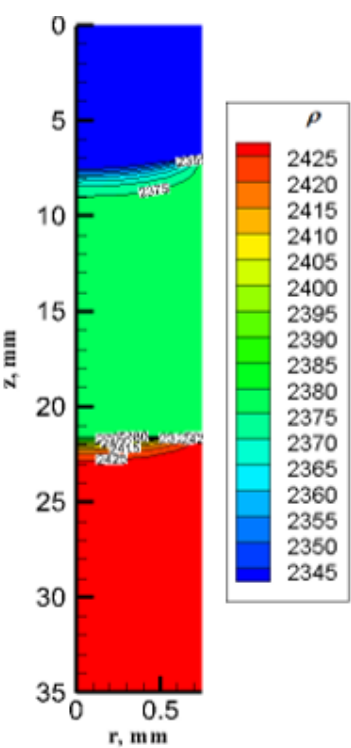

(b)

Fig. 2. Temperature (a) and density (b) distribution of the $\mathrm{BeO}$ slip in the flat cavity at the binder concentration of $\omega=0.100$ and the casting speed $u=3.083 \mathrm{~mm} / \mathrm{s}$

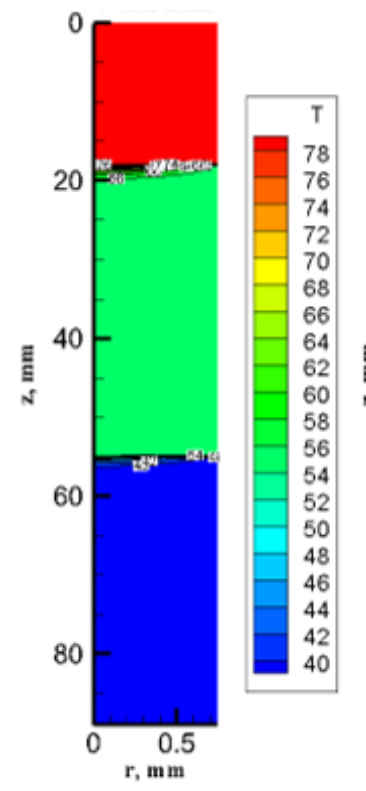

(a)

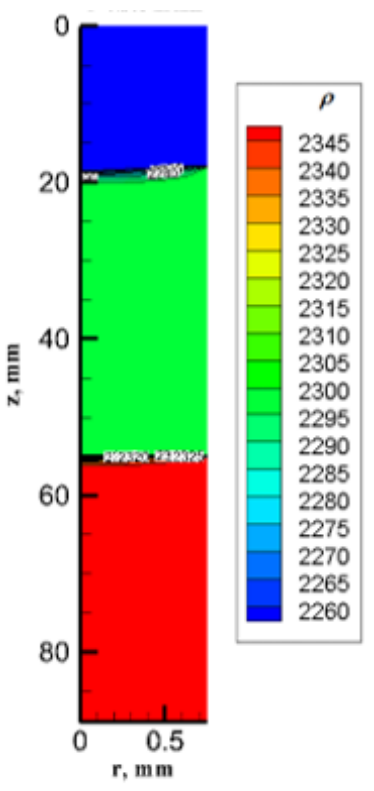

(b)

Fig. 3. Temperature (a) and density (b) distribution of the $\mathrm{BeO}$ slip in the flat cavity at the binder concentration of $\omega=0.117$ and the casting speed $u=2.75 \mathrm{~mm} / \mathrm{s}$

In this case, the transition zones from the hot field to the warm one and from the warm field to cold one for a slip density occupy a narrower region. This indicates the absence of blow holes or shrinkage porosity in the slip mass of beryllium oxide that is sound casting of beryllium oxide ceramics is obtained, as in the experimental studies [1]. 


\section{Discussion of Calculation Results}

Figure 4 and Figure 5 show the temperature distribution in the annular cavity for a three contour bushing with a cavity thickness of $r_{2}-r_{1}=1 \mathrm{~mm}$ at the casting speeds of $u=1.542 \mathrm{~mm} / \mathrm{s} ; 3.083 \mathrm{~mm} / \mathrm{s}$; $6.167 \mathrm{~mm} / \mathrm{s}$, and the binder concentration $\omega=0.100$ (see Figure 4); as well as at the casting speeds of $1.375 \mathrm{~mm} / \mathrm{s} ; 2.75 \mathrm{~mm} / \mathrm{s} ; 5.5 \mathrm{~mm} / \mathrm{s}$, and the binder concentration $\omega=0.117$ (see Figure 5). Water temperatures in the cooling circuits are equal to $\theta_{1}=80^{\circ} \mathrm{C} ; \theta_{2}=54^{\circ} \mathrm{C}, \theta_{3}=40^{\circ} \mathrm{C}$.

The slip temperature at the entrance to the annular cavity is constant along the cross-section, and which is equal to $t=t_{0}$. In the first cooling circuit, the wall temperature is equal to $80^{\circ} \mathrm{C}$ and the temperature field is constant in this region (see Figure 4 and Figure 5). In the second cooling circuit, the wall temperature is equal to $54^{\circ} \mathrm{C}$. The dynamic viscosity $\mu(t)$, density $\rho(t)$ and yield stress $\tau_{0}(t)$ of the slip increase with decreasing temperature, and the slip solidifying clearly begins to appear. The slip slides along the wall of the cavity. The longitudinal velocity component will be constant across the cavity section.

A growth of heat removal of wall in the second cooling circuit leads to a reduction of the temperature (Figure 4 and Figure 5). There is a transition zone in the beginning of the second circuit, where the the temperature of the slip changing from $80^{\circ} \mathrm{C}$ to $56^{\circ} \mathrm{C}$ and determines upper limit of the slip crystallization. In the transition zone at the temperature range from $56^{\circ} \mathrm{C}$ to $42^{\circ} \mathrm{C}$, crystallization of the slip occurs.

As can be seen from Figure 6 and Figure 7 the slip density distribution increases with cooling and a decrease in temperature along the length of the annular cavity. The slip density increases during the transition from a liquid to a solid state and shows the process of solidifying of the $\mathrm{BeO}$ slip in the annular cavity. In the area of the first cooling circuit, the density field is constant. In the zone of the second cooling circuit, the slip crystallization takes place. In the zone of the third cooling circuit, the $\mathrm{BeO}$ slip solidifies and is in the solid state.

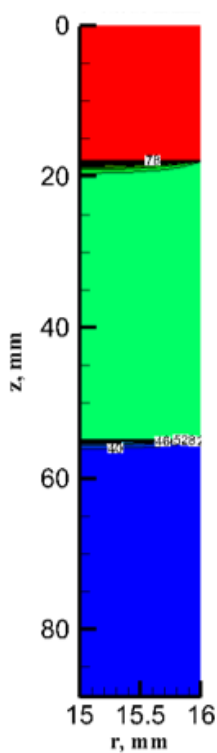

(a)

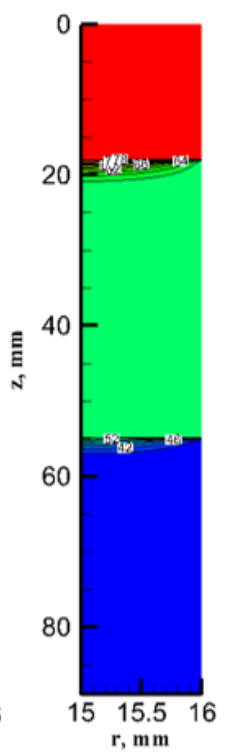

(b)

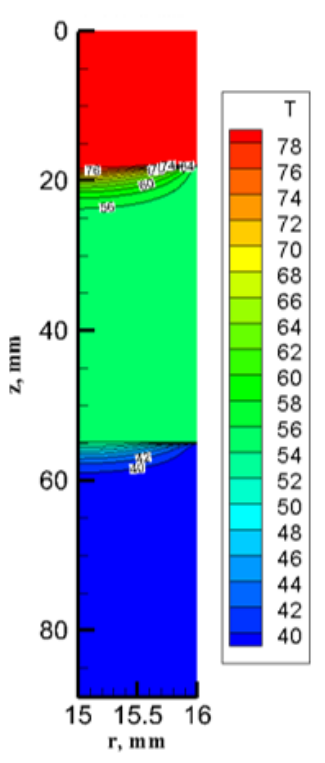

(c)

Fig. 4. Temperature distribution of the $\mathrm{BeO}$ slip in the annular cavity at the binder concentration of $\omega=0.100$ and the different casting speeds: a) $1.542 \mathrm{~mm} / \mathrm{s} ; 3.083 \mathrm{~mm} / \mathrm{s} ; 6.167 \mathrm{~mm} / \mathrm{s}$ 


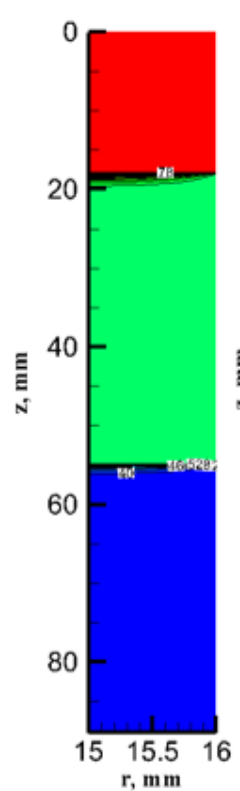

(a)

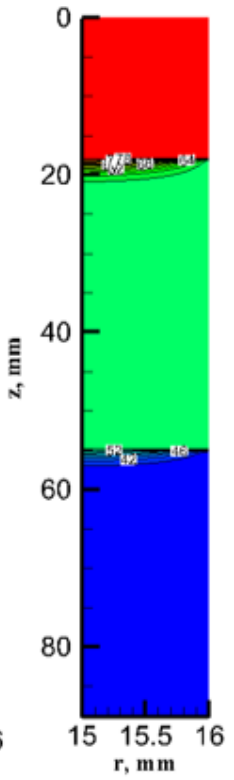

(b)

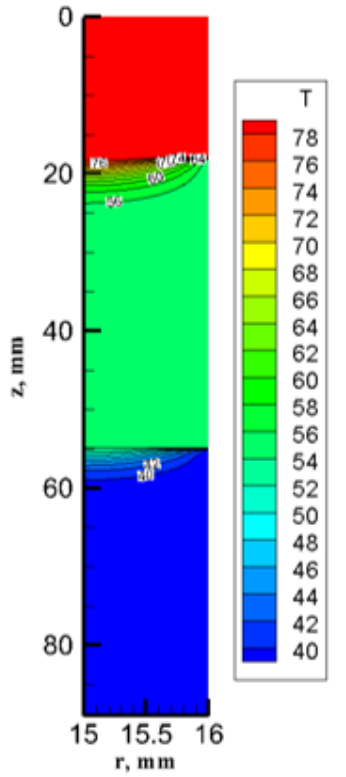

(c)

Fig. 5. Temperature distribution of the $\mathrm{BeO}$ slip in the annular cavity at the binder concentration of $\omega=0.117$ and the different casting speeds: a) $1.375 \mathrm{~mm} / \mathrm{s}$; b) $2.75 \mathrm{~mm} / \mathrm{s}$; c) $5.5 \mathrm{~mm} / \mathrm{s}$

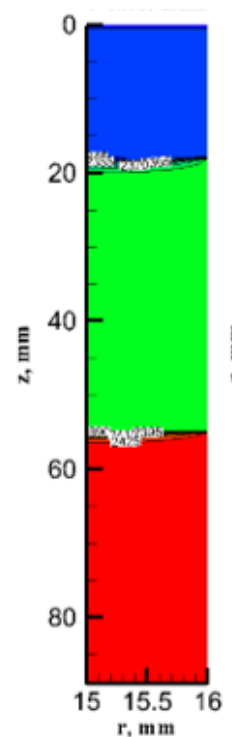

(a)

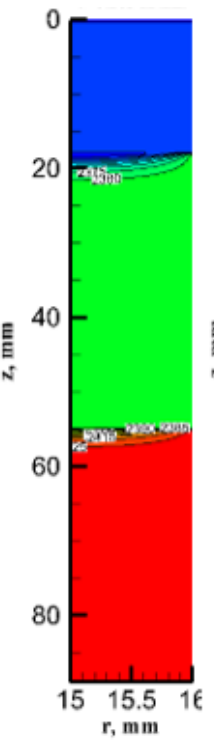

(b)

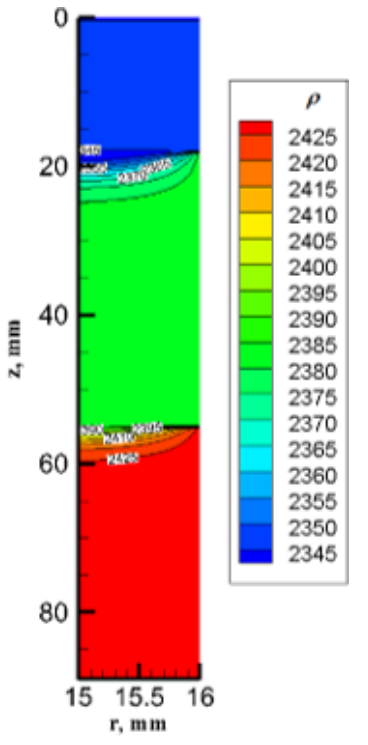

(c)

Fig. 6. Density distribution of the $\mathrm{BeO}$ slip in the annular cavity at the binder concentration of $\omega=$ 0.100 and the different casting speeds: a) 1.542 $\mathrm{mm} / \mathrm{s}$; b) $3.083 \mathrm{~mm} / \mathrm{s}$; c) $6.167 \mathrm{~mm} / \mathrm{s}$

The density distributions of the slip at different thicknesses of the annular cavity are shown in Figure 8. An increase in the thickness of the annular cavity leads to an expansion of the slip crystallization zone. The zone of solid state shows a density packing of the slip (see Figure 8). 


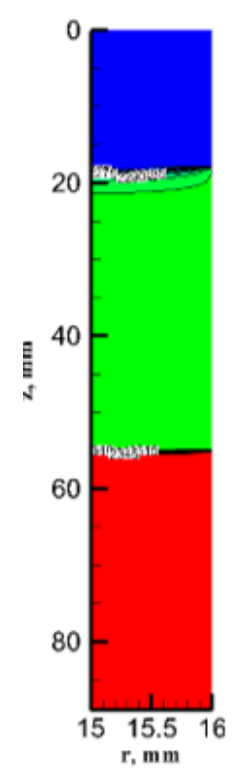

(a)

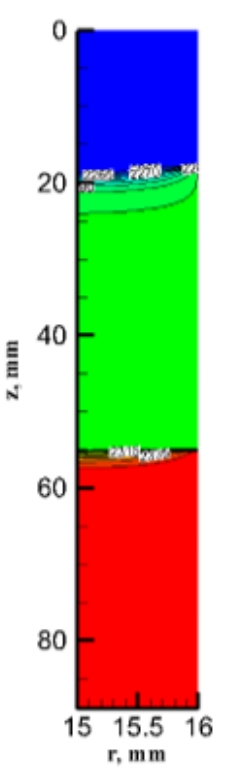

(b)

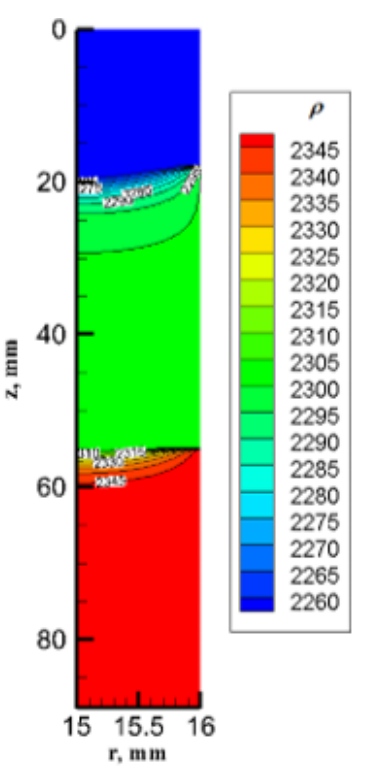

(c)

Fig. 7. Density distribution of the $\mathrm{BeO}$ slip in the annular cavity at the binder concentration of $\omega=$ 0.117 and the different casting speeds: a) 1.375 $\mathrm{mm} / \mathrm{s}$; b) $2.75 \mathrm{~mm} / \mathrm{s}$; c) $5.5 \mathrm{~mm} / \mathrm{s}$

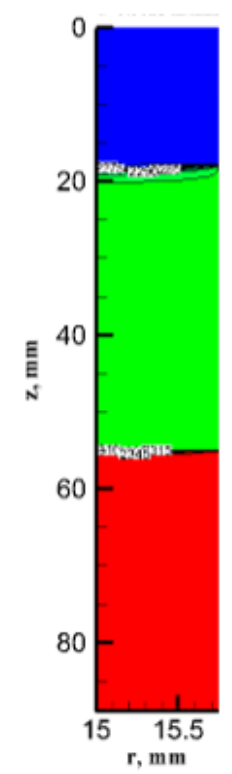

(a)

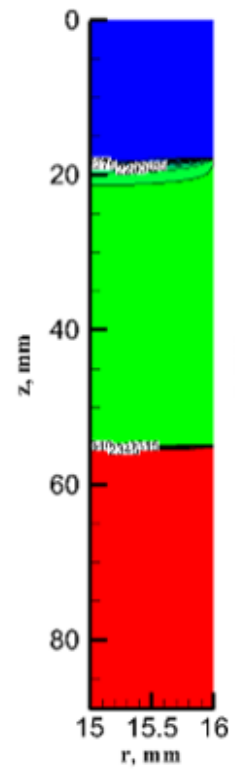

(b)

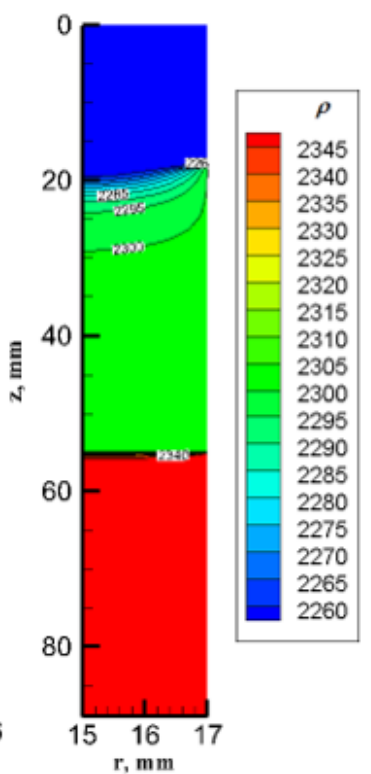

(c)

Fig. 8. Density field of the $\mathrm{BeO}$ slip in the annular cavity at different cavity thicknesses, the casting speed $u=1.375 \mathrm{~mm} / \mathrm{s}$ and the binder concentration $\omega=0.117$

\section{Comparison of Calculation Results with Experiment}

Specific surface area of the powder described in Table 1 has an optimal value for obtaining the ceramic fabrication of good soundness. Experiments show that at other values of specific surface area of the powder, weight content of binder increases or ceramic crumbling occurs due to presence of micropores and fractures [1]. 
The experimental data for the slip viscosity and molding capacity values, molding velocities for different weigh fractions of binder in slip are presented in Table 2 for the annular cavity molding process (see Figure 9). These data show that for each mass fraction of the binder corresponds to the optimal value of the casting speed, providing mechanical strength of the casting during molding.

\section{Table 2}

Parameters of slip of beryllium oxide depending on the casting speed

\begin{tabular}{lllll}
\hline $\begin{array}{l}\text { The weight content of } \\
\text { the binder in the slip, } \\
\% \text { wt }\end{array}$ & $\begin{array}{l}\text { Slip viscosity at } \mathrm{T}_{0} \\
=80^{\circ} \mathrm{C}, \mathrm{Pa} \cdot \mathrm{s}\end{array}$ & $\begin{array}{l}\text { Slip molding } \\
\text { capacity, } \mathrm{mm}\end{array}$ & $\begin{array}{l}\text { Casting speed, } \\
\mathrm{m} / \mathrm{min}\end{array}$ & $\begin{array}{l}\text { Flexural strength of } \\
\text { the cast, } \mathrm{mPa}\end{array}$ \\
\hline 0.100 & 5.76 & 35 & 0.185 & 9.33 \\
0.117 & 2.80 & 89 & 0.165 & 8.17 \\
\hline
\end{tabular}

The temperature and the density distributions of the slip in the annular cavity have been obtained at a casting speed $u=3.083 \mathrm{~mm} / \mathrm{s}$, cavity thickness $0.75 \mathrm{~mm}$, and bond concentration $\omega=0.100$ (see Figure 9).

Figure 9 shows the areas of the slip temperature and density transition from one cooling circuit to another. In the third circuit zone there is a uniform distribution of temperature and density over the cross section of the casting. The structural-mechanical property of the casting will be uniform and result in uniform shrinkage of the beryllium oxide ceramics at the exit of the casting mold. Therefore, holes and voids, leading to a loss of strength of the casting, are not formed.

Similar data were obtained in the annular cavity at a casting speed of $u=2.75 \mathrm{~mm} / \mathrm{s}$, a cavity thickness of $0.75 \mathrm{~mm}$, and a binder concentration of $\omega=0.117$ (see Figure 10). A uniform temperature and density distribution in the solidification zone of the beryllium oxide slip is also seen here. The calculations show that the slip hardens in the casting mold. This means that the ceramics made of $\mathrm{BeO}$ has shaped the structural form for further treatment.

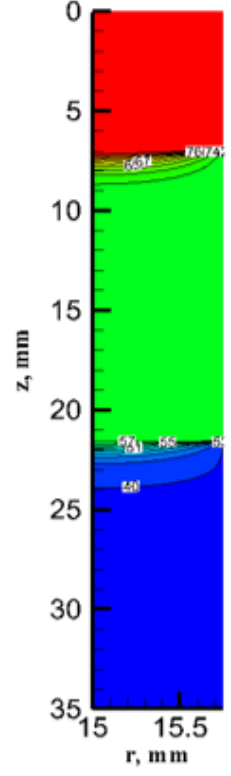

(a)

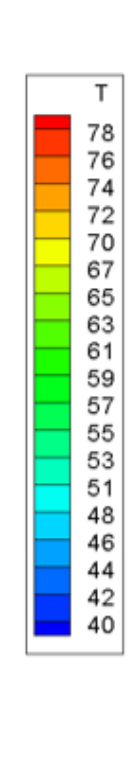

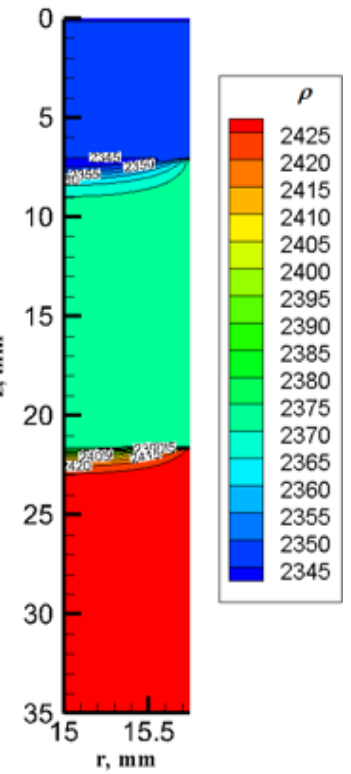

(b)

Fig. 9. Distributions of the temperature (a) and density (b) of the BeO slip in the annular cavity at $u=3.083 \mathrm{~mm} / \mathrm{s} ; \omega=0.100$ 


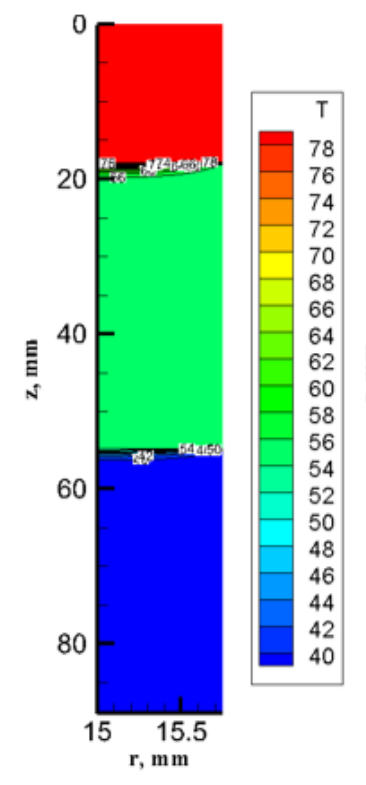

(a)

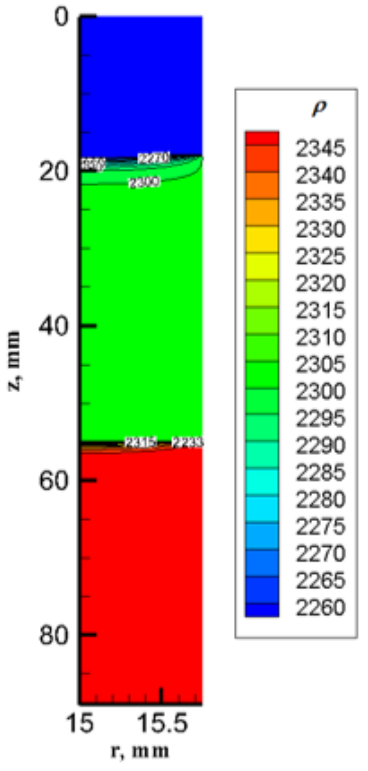

(b)

Fig. 10. Distribution of the temperature (a) and density (b) of the $\mathrm{BeO}$ slip in the annular cavity at $u=2.75 \mathrm{~mm} / \mathrm{s} ; \omega=0.117$

\section{Conclusion}

Rheological (viscosity, limiting friction stress) and thermophysical (density, thermal conductivity, heat capacity) properties of a slip made of thermoplastic beryllium oxide were obtained on the basis of experimental data and generalized in the form of empirical formulas, as in the works [23-26].

The thermomechanical model of a casting describes the motion and heat transfer of a thermoplastic suspension of beryllium oxide in a molding cavity in a liquid, taking into account crystallization and viscous-plastic states. The calculated data at different casting rates are consistent with experimental data and confirm the physical validity and correctness of the thermomechanical model.

The calculation results show a state change of a thermoplastic slip of beryllium oxide during casting using ultrasonic activation. At the beginning of the forming cavity section of the casting installation, the thermoplastic slip is in a liquid state. In accordance with the thermal condition of casting the slip begins to cool and, as it moves along the cavity, has a crystallization zone with a transition to a viscous-plastic state. The density of the slip mass increases with the transition from a liquid to a viscous-plastic state. This density distribution expresses the mechanism of volumetric changes in the slip and is in satisfactory agreement with the experiment [1].

Analysis of the results shows that it is possible to control the process of solidification of a beryllium oxide slip in an injection mold by adjusting the flow rate, casting speed and thermal cooling mode. In the calculations, it can be found the optimal conditions for the process of molding ceramics by hot casting, which allow to obtain a hardened product with a uniform structure at the output [1].

\section{References}

[1] Shakhov, S. A., and G. D. Bitsoev. "Application of ultrasound in the manufacture of high thermal conductivity ceramic articles." Ust'-Kamenogorsk (1999). 
[2] Kiiko, V. S., Makurin Yu, and Ivanovsky A. "Beryllium Oxide Ceramics: production, physico-chemical properties, application." Yekaterinburg: Ural Branch of the Russian Academy of Sciences (2006).

[3] Shakhov, S. A. "Controlling the deformation behavior of thermoplastic slips with ultrasound." Glass and Ceramics 64, no. 9-10 (2007): 354-356.

https://doi.org/10.1007/s10717-007-0088-2

[4] Shakhov, S. A. "Use of ultrasound in order to intensify molding of high-temperature thermocouple sheaths." Refractories and Industrial Ceramics 49, no. 4 (2008): 261-264.

https://doi.org/10.1007/s11148-008-9074-7

[5] Shakhov, S. A., and A. E. Gagarin. "Rheological characteristics of thermoplastic disperse systems treated with ultrasound." Glass and Ceramics 65, no. 3-4 (2008): 122-124.

https://doi.org/10.1007/s10717-008-9030-5

[6] Akishin, G. P., S. K. Turnaev, V. Ya Vaispapir, V. S. Kiiko, I. R. Shein, E. D. Pletneva, M. N. Timofeeva, and A. L. Ivanovskii. "Composition of beryllium oxide ceramics." Refractories and Industrial Ceramics 51, no. 5 (2011): 377 381.

https://doi.org/10.1007/s11148-011-9329-6

[7] Akishin, G. P., S. K. Turnaev, V. Ya Vaispapir, M. A. Gorbunova, Yu N. Makurin, V. S. Kiiko, and A. L. Ivanovskii. "Thermal conductivity of beryllium oxide ceramic." Refractories and Industrial Ceramics 50, no. 6 (2009): $465-468$. https://doi.org/10.1007/s11148-010-9239-z

[8] Shah, Arman, S. Izman, and M. A. Hassan. "Influence of nitrogen flow rate in reducing tin microdroplets on biomedical TI-13ZR-13NB alloy." Jurnal Teknologi 78, no. 5-10 (2016). https://doi.org/10.11113/jt.v78.8825

[9] Shah, A., S. Izman, and S. N. Fasehah. "Study on micro droplet reduction on tin coated biomedical TI-13ZR-13NB alloy." Jurnal Teknologi 78, no. 5-10 (2016): 1-5.

https://doi.org/10.11113/jt.v78.8824

[10] German, Randall M., and Animesh Bose. Injection Molding of Metals and Ceramics. Metal Powder Industries Federation, New Jersy: Princeton, 1997.

[11] Zhapbasbayev, Uzak, Gaukhar Ramazanova, Bagdaulet Kenzhaliev, Zamira Sattinova, and Sergei Shakhov. "Experimental and calculated data of the beryllium oxide slurry solidification." Applied Thermal Engineering 96 (2016): 593-599.

https://doi.org/10.1016/i.applthermaleng.2015.11.114

[12] Voller, Vaughan R., and C. Prakash. "A fixed grid numerical modelling methodology for convection-diffusion mushy region phase-change problems." International Journal of Heat and Mass Transfer 30, no. 8 (1987): 1709-1719. https://doi.org/10.1016/0017-9310(87)90317-6

[13] Voller, Vaughan R., C. R. Swaminathan, and Brian G. Thomas. "Fixed grid techniques for phase change problems: a review." International Journal for Numerical Methods in Engineering 30, no. 4 (1990): 875-898. https://doi.org/10.1002/nme.1620300419

[14] Hu, Henry, and Stavros A. Argyropoulos. "Mathematical modelling of solidification and melting: a review." Modelling and Simulation in Materials Science and Engineering 4, no. 4 (1996): 371-396.

https://doi.org/10.1088/0965-0393/4/4/004

[15] Moraga, Nelson O., Marcos A. Andrade, and Diego A. Vasco. "Unsteady conjugate mixed convection phase change of a power law non-Newtonian fluid in a square cavity." International Journal of Heat and Mass Transfer 53, no. 1516 (2010): 3308-3318.

https://doi.org/10.1016/j.ijheatmasstransfer.2010.02.044

[16] Carmona, Mauricio, and Cristóbal Cortés. "Numerical simulation of a secondary aluminum melting furnace heated by a plasma torch." Journal of Materials Processing Technology 214, no. 2 (2014): 334-346.

https://doi.org/10.1016/j.jmatprotec.2013.09.024

[17] Bannach, Nancy. "Phase Change: Cooling and Solidification of Metal." Comsol Blog, August 12 (2014).

[18] Dvinskikh, Yu. V., R. Ya. Popil'skii, L. I. Kostin, and V. V. Kulagin. "The thermophysical properties of thermoplastic cast slips of some highly refractory oxides." Ogneupory 12 (1979): 37-44.

https://doi.org/10.1007/BF01400294

[19] Wilkinson, W. L. Non-Newtonian Fluids. Hydrodynamics, Mixing and Heat Transfer. Moscow: Mir, 1964.

[20] Cebeci, Tuncer, and Peter Bradshaw. Physical and Computational Aspects of Convective Heat Transfer. New York: Springer-Verlag Berlin Heidelberg, 1984.

https://doi.org/10.1007/978-3-662-02411-9

[21] Anderson, Dale, John C. Tannehill, and Richard H. Pletcher. Computational Fluid Mechanics and Heat Transfer. CRC Press, 1990.

[22] Chung, T. J. Computational Fluid Dynamics. Cambridge University Press, 2002. 
https://doi.org/10.1017/CBO9780511606205

[23] Ergozhin, E. E., B. K. Kenzhaliev, T. K. Chalov., K. Sh. Akhmetova, and T. V. Kovrigina. "High-permeability polyelectrolite for extraction of gold ions and accompanying metals from cyan solutions of heap leaching." Tsvetnye Metally 2 (2005): 43-46.

[24] Kenzhaliev, B. K., E. I. Kul'deev, V. A. Luganov, I. V. Bondarenko, I. Yu Motovilov, and S. S. Temirova. "Production of Very Fine, Spherical, Particles of Ferriferous Pigments from the Diatomaceous Raw Material of Kazakhstan." Glass and Ceramics 76, no. 5-6 (2019): 194-198.

https://doi.org/10.1007/s10717-019-00163-w

[25] Volodin, V. N., Tuleushev Y. Zh, B. K. Kenzhaliyev, and S. A. Trebukhov. "Thermal degradation of hard alloys of the niobium-cadmium system at low pressure." Kompleksnoe Ispol'zovanie Mineral'nogo syr'â = Complex Use of Mineral Resources 1, no. 312 (2020): 41-47.

https://doi.org/10.31643/2020/6445.05

[26] Kenzhaliyev, B. K., T. Yu Surkova, and D. M. Yessimova. "Concentration of rare-earth elements by sorption from sulphate solutions." Kompleksnoe Ispol'zovanie Mineral'nogo syr'â = Complex Use of Mineral Resources 3 (2019): 5-9.

https://doi.org/10.31643/2019/6445.22 